\title{
Degradation and Detoxification of Three Textile Azo Dyes by Mixed Fungal Cultures from Semi-Arid Region of Brazilian Northeast
}

\author{
Carlos Nascimento ${ }^{1,2}$, Danielly de Paiva Magalhães $^{3}$, Martha Brandão ${ }^{4}$, André Batouli \\ Santos $^{4}$, Marcia Chame ${ }^{4}$, Darcílio Baptista ${ }^{3}$, Marília Nishikawa ${ }^{1}$ and Manuela da Silva ${ }^{2^{*}}$ \\ ${ }^{I}$ Departamento de Microbiologia; Instituto Nacional de Controle de Qualidade em Saúde; Fundação Oswaldo \\ Cruz; Avenida Brasil, 4365; Manguinhos - RJ - Brasil. ${ }^{2}$ Programa de Pós-Graduação em Vigilância Sanitária; \\ Instituto Nacional de Controle de Qualidade em Saúde; Fundação Oswaldo Cruz; Avenida Brasil, 4365; \\ Manguinhos - RJ - Brasil. ${ }^{3}$ Laboratório de Avaliação e Promoção da Saúde Ambiental; Instituto Oswaldo Cruz; \\ Fundação Oswaldo Cruz; Avenida Brasil, 4365; Manguinhos - RJ - Brasil. ${ }^{4}$ Laboratório de Ecologia Gustavo de \\ Oliveira Castro; Departamento de Endemias Samuel Pessoa; Escola Nacional de Saúde Pública; Fundação \\ Oswaldo Cruz; Rua Leopoldo Bulhões, 1480; Manguinhos - RJ - Brasil
}

\begin{abstract}
The aim of this work was to study the degradation and detoxification of three textile azo dyes (Reactive Red 198, Reactive Red 141 and Reactive Blue 214) by mixed fungal cultures from semi-arid region of Brazilian Northeast. Sediment samples of twenty water reservoirs in the surroundings of Serra da Capivara National Park, area of environmental preservation in the caatinga in the State of Piauí, with semi-arid climate, were evaluated in order to select the consortia of fungi capable to degrade and detoxify these dyes. The mixed fungal culture from Caldeirão Escuridão (CE) reservoir was the most efficient in the degradation and detoxification of the dyes tested.
\end{abstract}

Key words: Fungi, Mycoremediation, Azo dyes, Degradation, Detoxification

\section{INTRODUCTION}

The contamination of pristine waters has been one of the major problems of modern society. The textile industry generates large volumes of wastewater, which if not properly treated, can cause serious problems of environmental contamination (Kunz et al., 2002). The pollution potential of textile dyes and intermediates compounds was first raised due to its toxicity and carcinogenicity that can cause damage to human health and environment (Banat et al., 1996). This is mainly due to the fact that many dyes are manufactured from known carcinogens such as benzidine, naphthalene and other aromatic compounds. Thus, the development of treatment technologies suitable for the removal of color and reduction of toxicity of textile effluents is important. The development of decolorization technologies depends on a sound scientific knowledge. Given the technical and economic needs, several new technologies involving physical, chemical and biological agents are being proposed and tested in various stages of

*Author for correspondence: manueladasilva@fiocruz.br 
commercialization. Meanwhile, a broad validation and integration of different methods of treatment will be needed to make these technologies both efficient and economically viable (Anjaneylu et al., 2005).

In recent years, several studies have focused on the use of microorganisms that are capable to biodegrade and/or bioaccumulate toxic compounds (Aksu, 2005). The bioremediation technology offers several advantages; it can be performed on site; generally has lower cost and minimum inconvenience in the process; eliminates the waste permanently; can be used in conjunction with methods of physical and chemical treatments; has minimal environmental impact and, therefore, has good public acceptance, with the regulatory encouragement (Boopathy, 2000; Dias, 2000).

Nevertheless, this process has some limitations. Certain chemical compounds are not susceptible to the bioremediation, for example, heavy metals, radio nucleotides and some chlorinated compounds; the time needed to develop effective systems for the target compounds can be long. In addition, there are problems related to the scale-up from the laboratory to the field. Besides this, in some cases, the microbial metabolism can produce more toxic metabolites that the original compound (Boopathy, 2000). Therefore, toxicological tests should be applied to track the level of toxicity resulting from this transformation. In this context, eco-toxicological studies using micro-crustacean species of the genus Daphnia have been conducted (Cooman et al., 2003; Shiny et al., 2005; Han et al., 2006).

On account of the efficiency of fungi in the process of decolorization, mainly because of their enzyme system that enables the degradation of various toxic compounds, including those that contain aromatic amines in its structure, for not producing material that has to be discarded. Furthermore, the method has generally public acceptance, which makes the treatment using fungia promising alternative to replace or complement the conventional treatments $(\mathrm{Fu}$ and Viraraghavan, 2001). However, more studies are needed on the ability of fungi regarding decolorization and detoxification of dyes used by the textile industry. Many works relate the potential for decolorization of fungi from already impacted areas (Yang et al., 2005; Lucas et al., 2006). However, results obtained with fungi from non-impacted areas have also shown to be promising (Junghanns et al., 2007; Pajot et al., 2007).

Brazil has in its territory a diversity of ecosystems whose richness is not yet fully known, for example, the caatinga in the semi-arid region. The caatinga comprises almost $10 \%$ of the total area of the Brazilian territory, with approximately 740,000 $\mathrm{Km}^{2}$. The main characteristic of this semi-arid region is the irregularity of the inter-annual rain and its repercussions; the rainfalls are below 1,200 $\mathrm{mm}$ and the dry season lasts five to six months (Pessis, 1998).

In the semi-arid regions, found in tropical countries, usually the organisms are more resistant to osmotic pressure and more adapted to specific conditions of $\mathrm{pH}$ and salinity. Thus fungi from these regions have become promising targets for bioprospection for possible use in the bioremediation of areas contaminated by textile dyes and other recalcitrant substances (Gusmão and Maia, 2006). The purpose of the present study was to evaluate the ability of decolorization and detoxification of mixed cultures of fungi obtained from sediment samples of pristine water reservoirs in the semi-arid region of the surroundings of Serra da Capivara National Park, an area protected by the Foundation of the American Man Museum FUMDHAM, therefore, free of anthropic impacts.

\section{MATERIALS AND METHODS}

\section{Collection of samples of sediment}

Samples of sediment were collected from 20 natural reservoirs in the area between the plains and in front of the cuesta of Serra da Capivara, in the surroundings of the Serra da Capivara National Park. The sediment samples were collected in duplicate in sterile polypropylene tubes with 50 $\mathrm{mL}$ of capacity. They were stored in Styrofoam box with ice until processed.

\section{Culture Media and Reagents}

Sabouraud Dextrose Broth (SDB) (1\% of peptone and $4 \%$ of dextrose) with chloramphenicol (400

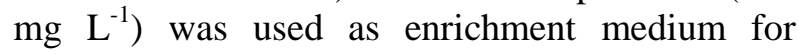
isolating the fungi present in the sediment samples. Potato Dextrose Broth (PDB) (20\% of potato and $2 \%$ of dextrose) was used for the preselection of mixed fungal cultures from the sediment samples (Kim et al., 1995; Zheng et al., 1999). Stock solutions of the dyes were prepared at 5\% for the Reactive Red 198 and Reactive Red 
141, both manufactured by DyStar (Brazil), and at $4 \%$ for Reactive Blue 214, manufactured by Clariant (Brazil). These solutions were sterilized by filtering through membrane of $0.22 \mu \mathrm{m}$ and used in the final concentration of $100 \mathrm{mg} \mathrm{L}^{-1}$. The chemical structures are shown in Figure 1.

b.
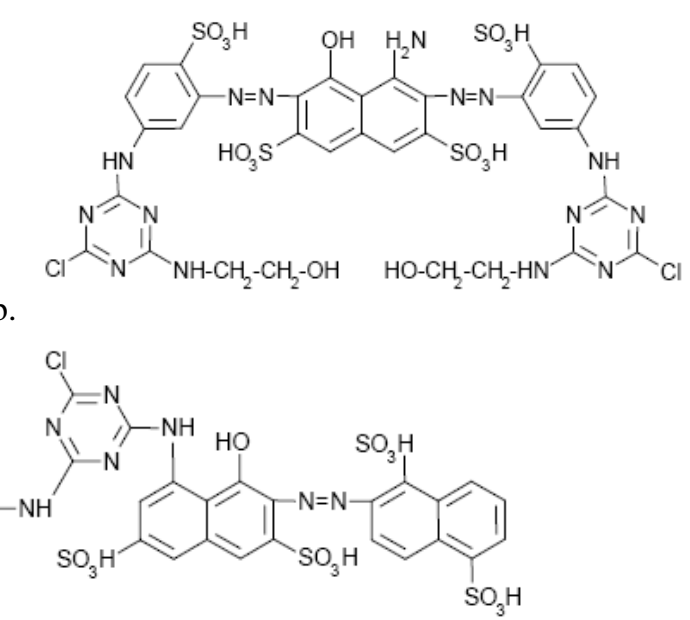

c.

Figure 1 - Structures of dyes: a. Reactive Red 198; b. Reactive Blue 214; c. Reactive Red 141.

\section{Selection of fungal cultures from the sediment samples}

From each sample, $30 \mathrm{~g}$ of sediment were transferred to $270 \mathrm{~mL}$ of sterile water. After blending for approximately $2 \mathrm{~min}$ in sterilized stainless steel cup, $2 \mathrm{~mL}$ of the mixture was inoculated in $400 \mathrm{~mL}$ of Sabouraud Dextrose Broth (SDB) medium with chloramphenicol (400 $\mathrm{mg} \mathrm{L}^{-1}$ ) and incubated for at $28^{\circ} \mathrm{C}$ for five days on a rotary shaker (New Brunswich, Innova 4335, USA) at $140 \mathrm{rpm}$.

At the end of the incubation, $3 \mathrm{~mL}$ of the culture was transferred to $100 \mathrm{ml}$ of Potato Dextrose Broth medium (PDB) supplemented with $100 \mathrm{mg}$ $\mathrm{L}^{-1}$ of Reactive Red 198 (RR198), in duplicate and then incubated at $28^{\circ} \mathrm{C}$ for seven days on a rotary shaker at $140 \mathrm{rpm}$ in the dark. Control experiments were conducted incubating PDB medium without fungi with the same concentrations of the dye tested.After the incubation, $2 \mathrm{~mL}$ aliquots of the cultures were centrifuged at $10,000 \mathrm{x}$ g for $10 \mathrm{~min}$ and $0.5 \mathrm{~mL}$ of supernatant was diluted 10 times in distilled water for analysis using a UV/VIS spectrophotometer (Shimadzu - UV-1601, Japan).

The culture medium with dye and without inoculum was used as a negative control and medium without dye and without inoculum was used as blank. The maximum wavelength used for the absorbance ratios of RR198 was $520 \mathrm{~nm}$. The spectra were read between 200 to $700 \mathrm{~nm}$ of absorbance (Máximo et al. 2003). Decolorization activity (\%) was calculated as described below:

Decolorization activity $(\%)=(\mathrm{A}-\mathrm{B}) / \mathrm{A} \times 100$

Where: $\mathrm{A}=$ initial absorbance and $\mathrm{B}=$ observed absorbance.

\section{Study of dye decolorization by the selected mixed fungal cultures}

The mixed fungal cultures able to decolorize the dye RR198 above $90 \%$ and without characteristics of adsorption, observed visually, were tested with the other two dyes, Reactive Red 141 (RR141), with maximum wavelength of $548 \mathrm{~nm}$, and Reactive Blue 214 (RB214), with maximum wavelength of $608 \mathrm{~nm}$.

Aliquots of $0.1 \mathrm{~mL}$ from the mixed fungal cultures grown in SDB, which were previously preserved at $-70^{\circ} \mathrm{C}$, were used to inoculate $50 \mathrm{~mL}$ of PDB and incubated at $28^{\circ} \mathrm{C}$ for five days on a rotary shaker at $140 \mathrm{rpm}$. Then the cultures were used in the same way as described above.

\section{Toxicology Evaluation of Culture Medium After Fungal Treatment}

Toxicological tests were conducted to evaluate the level of toxicity after dye decolorization by the mixed fungal cultures, using the test of acute toxicity with the micro-crustacean Daphnia pulex. The tests followed the OECD 202 protocol (OECD, 2004). 
Stock of $D$. pulex was originally obtained from the Carolina Biological Supply (North Carolina, USA). The organisms were cultured in the germination chamber (347 CDG - Fanem, SP, Brazil), with constant temperature of $24{ }^{\circ} \mathrm{C}$ and photoperiod cycle 12:12h. The chlorophyte Ankistrodesmus falcatus, which was grown in Marine Biological Laboratory (MBL) medium (Stemberger 1981), was used for feeding D. pulex in concentration of $1.0 \mathrm{mg} \mathrm{C} \mathrm{l}^{-1}$. For the test, 20 neonates $(24 \mathrm{~h}$ old; in two replicates of 10 individuals) were used for test concentration. The time of exposure was $24 \mathrm{~h}$ under constant temperature of $24^{\circ} \mathrm{C}$ and under light. Using the static method in which there was no exchange of the medium during $24 \mathrm{~h}$. The toxicity factor for 24 $\mathrm{h}$ ( $\left.\mathrm{TF}_{\mathrm{D} 24 \mathrm{hs}}\right)$ was estimated, which was the least dilution of the sample from which no immobility or death occurred in more than $10 \%$ of the organisms.

\section{RESULTS AND DISCUSSION}

The dyes evaluated in the present study were chosen as representatives of dyes widely used commercially by the Brazilian textile industry. From these dyes, the Reactive Red 198, a monoazo, was chosen to select the fungal cultures present in the sediment samples due to its less complex structure compared to the two other azo dyes, which were used in the second part of the study.

The decolorization activity obtained by the selected cultures is shown in Table 1. Five mixed fungal cultures from CBI, CBII, CD, CG and CMZ decolorized $100 \%$ of RR198 after seven days incubation. From these samples, cultures CG and CMZ showed no dye adsorption by the biomass. On the other hand, dye adsorption was observed on the biomass of the other three cultures (Table $1)$.

Table 1 - Decolorization percentage of the dye RR198 by fungal cultures obtained from sediment samples over 7 days of incubation and their decolorization mechanism.

\begin{tabular}{lcc}
\multicolumn{1}{c}{ Sediment Samples } & \% decolorization & $\begin{array}{c}\text { Decolorazation } \\
\text { mechanism }\end{array}$ \\
\hline Caldeirão da Geladeira (CG) & 100,00 & $\begin{array}{c}\text { Degradation } \\
\text { Adsorption }\end{array}$ \\
Caldeirão da Barriguda I (CBI) & 100,00 & Adsorption \\
Caldeirão da Barriguda II (CBII) & 100,00 & Adsorption \\
Caldeirão do Desfiladeiro (CD) & 100,00 & Degradation \\
Caldeirão Manuel Zuza (CMZ) & 100,00 & Adsorption \\
Caldeirão do Abel da Minhosa do Zé Carlos (CAM) & 99,18 & Adsorption \\
Caldeirão Esquerdo do Fundo do Boqueirão da Pedra Furada (BPF) & 98,71 & Degradation \\
Caldeirão Deolindo Gongo (CDG) & 98,07 & Degradation \\
Caldeirão da Escuridão (CE) & 97,64 & Adsorption \\
Caldeirão do Veado Morto (CVM) & 97,13 & Adsorption \\
Caldeirão da Muriçoca (CM) & 96,65 & Adsorption \\
Centro de Visitantes (CV) & 96,04 & Degradation \\
Caldeirão do Perna (CP) & 91,60 & Adsorption \\
Caldeirão do Jacinto (CJ) & 89,52 & Adsorption \\
Olho d'Água do Cumbre (OAC) & 88,98 & Adsorption \\
Olho d'Água Gongo (OAG) & 87,20 & Adsorption \\
Caldeirão Apertado (CA) & 48,71 & Adsorption \\
Olho d'Água Serra Branca (OASB) & 34,68 & Adsorption \\
Bebedouro do Fundo do Pinga do Boi (BFPB) & 26,61 & Adsorption \\
Bebedouro Pinga da Escada (BPE) & 7,71 & \\
\hline
\end{tabular}

Despite the decolorization of $100 \%$, the cultures that adsorbed the dye were not considered satisfactory because this mechanism is not suitable for long term treatment, since there is accumulation of biomass with dye adsorbed that eventually will have to be discarded (Pearce et al. 2003).
The mixed fungal cultures from CAM, BPF, CDG, CE, CVM, CM, CV and CP decolorized between 90-99\% of the dye. Cultures CDG, CE and CP showed no adsorption, in spite of not decolorizing $100 \%$ of the dye. Mixed fungal cultures from CJ, $\mathrm{OAC}, \mathrm{OAG}, \mathrm{CA}, \mathrm{OASB}, \mathrm{BFPB}$ and $\mathrm{BPE}$ 
decolorized less than $90 \%$ of the dye and adsorbed the dye resulting in red biomass (Table 1).

The results of spectrophotometric analyses from CG, CMZ, CDG, CE and CP showed that the characteristic peak of the dye was transformed into a new peak (Fig. 2A and 2B) or it disappeared (Fig. 2C, 2D and 2E). Glenn and Gold (1983) have reported that degradation occurred when the

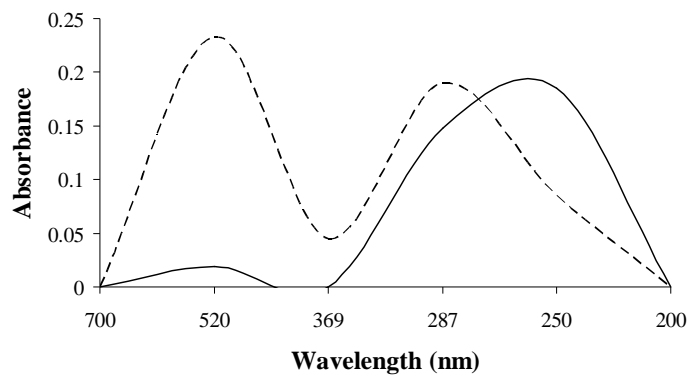

A - - Control RR198 — CP treatment

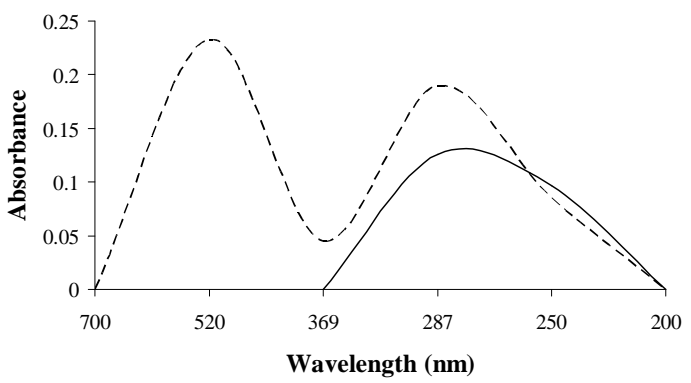

$\mathrm{C}$

- - Control RR198 - CDG treatment characteristic peak of absorption completely disappeared or a new peak appeared. Therefore, based on these results and the fact that they decolorized over $90 \%$ of the dye with no dye adsorption, it could be assumed that these five mixed fungal cultures degraded the dye RR198. These cultures were then tested with the other two dyes: RB214 and RR141.

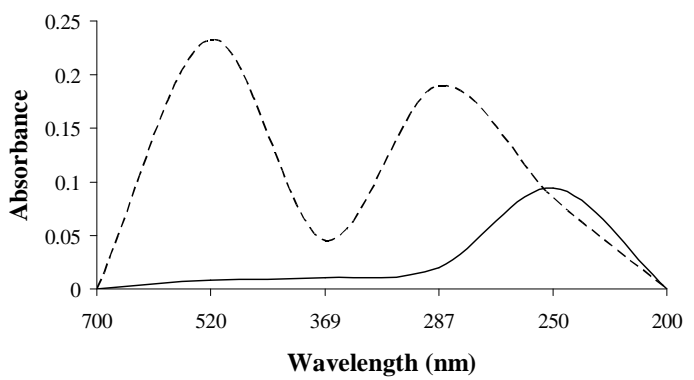

B

- Control RR198 — CE treatment

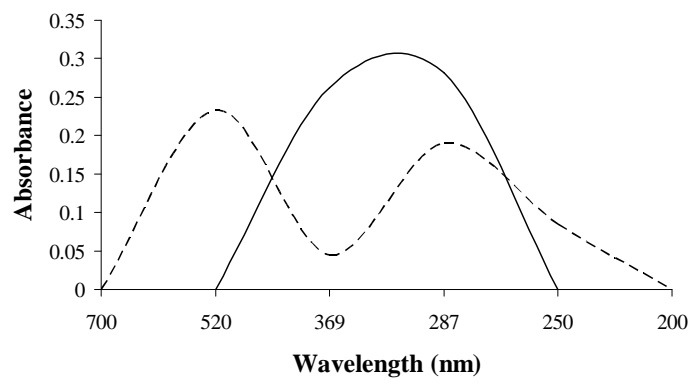

$\mathrm{D}$

- - Control RR198 - CG treatment

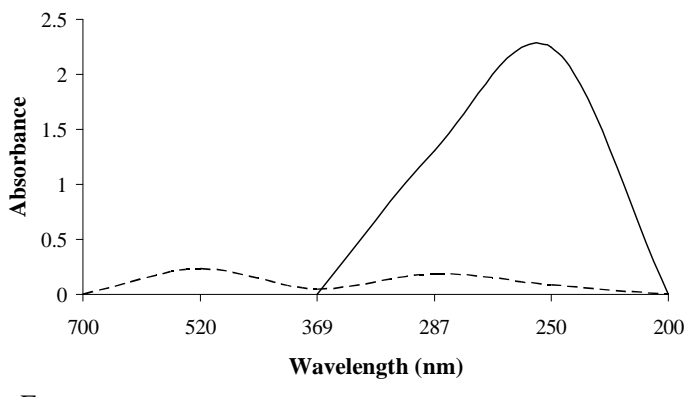

E

- - Control RR198 — CMZ treatment

Figure 2 - Espectra resulting from the RR198 degradation by the five fungal cultures from CP (A), CE (B), CDG (C), CG (D) and CMZ (E) together with the spectrum of RR198 control.

The complete disappearance of the characteristic peak of these dyes was observed only with the fungal cultures from CE (Fig. 3 and 4).

Despite the fact that the mixed fungal cultures of $\mathrm{CDG}, \mathrm{CG}, \mathrm{CMZ}$ and $\mathrm{CP}$ decolorized the dye RR198 with no dye adsorption by the biomass, these cultures adsorbed the dyes RB214 and RR141 (data not shown). This variation regarding dye decolorization could be due to the fact that these two dyes are diazo dyes with a more complex chemical structure than the monoazo RR198 has. Nozaki et al. (2008) have demonstrated that chemical structure of dyes affects their decolorization.

Asgher et al. (2007) evaluated the dye decolorization efficiency of mixed microbial 
consortia from wastewater treatment plants of different textile units and concluded that the microbial consortium is a robust process for the bioremediation of textile dye effluents. In another study on textile dye decolorization by microbial consortia the authors characterized the consortia and demonstrated that they were dominated by yeasts and that the use of fungal consortia was more efficient than traditional biological methods or systems using pure fungal strains (Yang et al., 2009).

In the present study, the mixed fungal cultures showed significant potential for decolorization, since $25 \%$ from the total samples tested achieved $>90 \%$ of decolorization of RR198 (100 mg L $\left.\mathrm{m}^{-1}\right)$, without features of dye adsorption by the biomass (Table 1). From these cultures, the most efficient was the CE mixed fungal culture, which presented decolorization for the three dyes tested with no dye adsorption and transformed the characteristic peak of RR198 to a new peak (Fig. 2B), and depleted completely the characteristic peaks of RB214 and RR141 (Fig. 3 and 4). These results confirmed that the mixed fungal culture from $\mathrm{CE}$ degraded the three azo dyes tested.

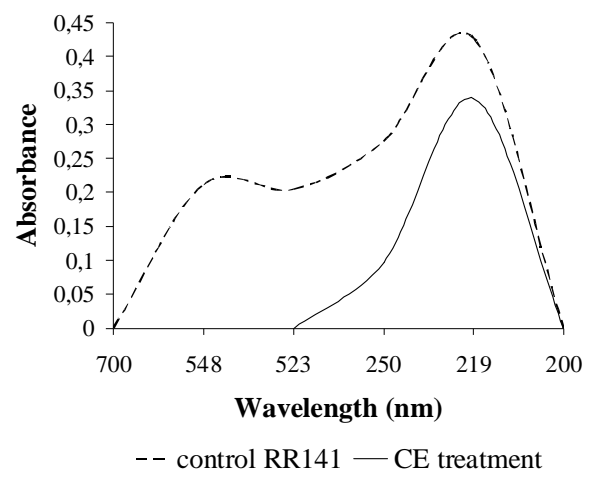

Figure 3 - Espectrum resulting from the RR141 degradation by the fungal culture from CE together with the spectrum of RR141 control.

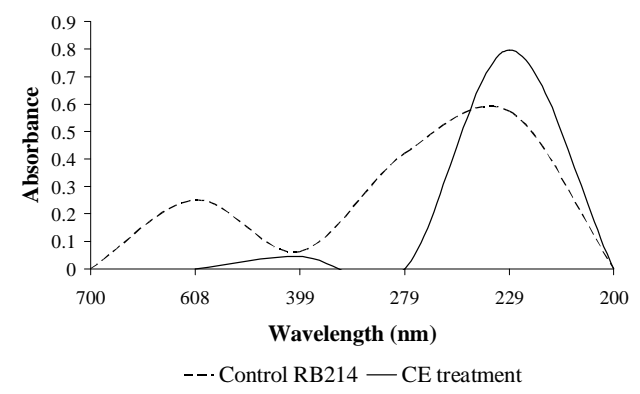

Figure 4 - Espectrum resulting from the RB214 degradation by the fungal culture from CE together with the spectrum of RB214 control.

Ecotoxicological tests should be conducted during the biodegradation processes to ensure that the products from degradation are less toxic than the original pollutant (Eichlerová et al., 2007). Considering that the decolorization is not always an indication of successful detoxification, a toxicity test with the dyes before and after their decolorization was performed in the present investigation.
The criterion used for the acute toxicity assay with Daphnia pulex was the toxicity factor for $24 \mathrm{~h}$ $\left(\mathrm{TF}_{\mathrm{D} 24 \mathrm{hs}}\right)$. The culture medium with the dye RR198 presented $\mathrm{TF}_{\mathrm{D} 24 \mathrm{hs}}$ of 14 that corresponded to $7 \mathrm{mg}$ $\mathrm{L}^{-1}$ of dye. After the treatment with the culture from $\mathrm{CE}$ the medium had its toxicity reduced to zero; therefore the detoxification of this dye by the fungi present in the CE culture was 100\% (Table 2). 
The remaining cultures were also able to detoxify the dye RR198, yet not as efficiently as CE culture. The CDG culture reduced $82.1 \%$ of dye toxicity, and the cultures from $\mathrm{CG}$ and $\mathrm{CP}$ reduced 76.4\%. The less effective, the CMZ culture, demonstrated $64.3 \%$ of toxicity reduction (Table
2). Regarding the dyes RB214 and RR141 the toxicological test was performed only for $\mathrm{CE}$ culture, given that it was the most efficient in the degradation of these dyes (Table 3) and in detoxifying the dye RR198 (Table 2).

Table $2-\mathrm{TF}_{\mathrm{D} 24 \mathrm{hs}}$ of RR198 before and after the treatment with the mixed fungal cultures and the percentage of toxicity reduction of the dye after fungal treatment.

\begin{tabular}{ccc}
\hline Samples & $\mathbf{T F}_{\mathbf{D}(\mathbf{2 4 h})}$ & Toxicity Reduction (\%) \\
\hline Control RR198 & 14.0 & - \\
CG & 3.3 & 76.4 \\
CE & No toxic & 100 \\
CDG & 2.5 & 82.1 \\
CP & 3.3 & 76.4 \\
CMZ & 5.0 & 64.3 \\
\hline
\end{tabular}

The dye RB214 presented $\mathrm{TF}_{\mathrm{D} 24 \mathrm{hs}}$ of 2 and the dye after the treatment with $\mathrm{CE}$ culture had a $\mathrm{TF}_{\mathrm{D} 24 \mathrm{~h}}$ of 1.8 , reducing $10 \%$ of the toxicity (Table 3 ). Nevertheless, the $\mathrm{TF}_{\mathrm{D} 24 \mathrm{~h}}$ of RR141 before and after the fungal treatment with CE culture was 2.6 for both; thus, there was no reduction of dye toxicity by the fungi present in CE culture (Table 3).
The fact that there was no reduction of toxicity in the case of RR141 demonstrated the importance of monitoring the toxicity before and after the biological treatments and that there was no direct correlation between the dye decolorization and detoxification as already discussed by Vanhulle et al. (2008).

Table $3-\mathrm{TF}_{\mathrm{D} 24 \mathrm{hs}}$ of RB214 and RR141 before and after the treatment with the mixed fungal culture from CE and the percentage of toxicity reduction of the dyes after fungal treatment.

\begin{tabular}{ccc}
\hline Sample & $\mathbf{T F}_{\mathbf{D}(24 \mathbf{h})}$ & Toxicity Reduction (\%) \\
\hline Control RB214 & 2.0 & - \\
CE & 1.8 & 10.0 \\
Control RR141 & 2.6 & - \\
CE & 2.6 & 0 \\
\hline
\end{tabular}

Based on these results it could be concluded that the most efficient mixed fungal culture, the $\mathrm{CE}$ culture, was efficient not just in dye degradation, but also in the detoxification of two dyes tested, demonstrating its good capacity to treat textile dye wastewaters. These results also indicated the surroundings of the Serra da Capivara National Park as an important source for bioremediation agents.

\section{ACKNOWLEDGEMENTS}

The present work was supported by a grant from CNPq (PAPES V - 403647/2008-8). The authors are indebted to DyStar industry (SP, Brazil) and Instituto Nacional de Tecnologia - INT (RJ, Brazil) for donating the dyes used in the present investigation. We also are thankful to Ludmila $\mathrm{R}$. Bergsten-Torralba for helping with the graphics.

\section{REFERENCES}

Anjaneyulu, Y.; Chary, N.S.; Raj, D.S.S. (2005), Decolourization of industrial effluents - available methods and emerging technologies - a review. Rev Environ Sci Biotechnol, 4, 245-273.

Aksu, Z. (2005), Application of biosorption for the removal of organic pollutants: a review. Process Biochem, 40, 997-1026.

Asgher, M.; Bhatti, H.N.; Shah, S.A.H.; Javaid Asad, M.; Legge, R.L. (2007), Decolorization potential of mixed microbial consortia for reactive and disperse textile dyestuffs. Biodegradation, 18, 311-316.

Banat, I.M.; Nigam, P.; Singh, D.; Marchant, R. (1996), Microbial decolorization of textile-dye-containing 
effluents: a review. Bioresource Technol, 58, 217 227.

Boopathy, R. (2000), Factors limiting bioremediation technologies. Bioresource Technol, 74, 63-67.

Cooman, K.; Gajardo, M.; Nieto, J.; Bornhardt, C.; Vidal, G. (2003), Tannery wastewater characterization and toxicity effects on Daphnia spp. Environ Toxicol, 18, n.1, 45-51.

Dias, A.E.X.O. (2000), Biorremediação de áreas afetadas por resíduos sólidos tóxicos. In- Resíduos sólidos, ambiente e saúde: uma visão multidisciplinar orgs. Sisinno, C.L.S.; Oliveira, R.M. Editora Fiocruz, Rio de Janeiro, pp. 79-98.

Eichlerová, I.; Homolka, L.; Benada, O.; Kofronová, O.; Hubálek, T.; Neruda, F. (2007), Decolorization of Orange $\mathrm{G}$ and Remazol Brilliant Blue R by the white rot fungus Dichomitus squalens: Toxicological evaluation and morphological study. Chemosphere, 69, 795-802.

Fu, Y.; Viraraghavan, T. (2001), Fungal decolorization of dye wastewaters: a review. Bioresource Technol, 79, 251-262.

Glenn, J.K.; Gold, M.H. (1983), Decolorization of several polymeric dyes by the lignin-degrading Basidiomycete Phanerochaete chrysosporium. Appl Environ Microbi, 45, 1741-1747.

Gusmão, L.F.P.; Maia, L.C. (2006), Diversidade $e$ caracterização dos fungos do semi-árido brasileiro. APNE, Recife.

Han, G.H.; Hur, H.G.; Kim, S.D. (2006), Ecotoxicological risk of pharmaceuticals from wastewater treatment plants in Korea: occurrence and toxicity to Daphnia magna. Environ Toxicol Chem, 25, n. 1, 265-271.

Junghanns, C.; Krauss, G.; Schlosser, D. (2007), Potential of aquatic fungi derived from diverse freshwater environments to decolourise synthetic azo and anthraquinone dyes. Bioresource Technol, 99, 1225-1235.

Kim, S.J.; Ishikawa, K.; Hirai, M.; Shoda, M. (1995), Characteristics of a newly isolated fungus, Geotrichum candidum Dec 1, which decolorizes various dyes. J Ferment Bioeng, 79, 601-607.

Kunz, A.; Peralta-Zamora, P.; Moraes, S.G.; Dúran, N. (2002), Novas tendências no tratamento de efluentes têxteis. Química Nova, 25, n.1, 78-82.

Lucas, M.S.; Amaral, C.; Sampaio, A.; Peres, J.A.; Dias, A.A. (2006), Biodegradation of the diazo dye Reactive Black 5 by a wild isolate of Candida oleophila. Enzyme Microb Tech, 39, 51-55.

Máximo, C.; Amorim, M.T.P.; Costa-Ferreira, M. (2003) Biotransformation of industrial reactive azo dyes by Geotrichum sp. CCMI 1019. Enzyme Microb Tech, 32, 145-151.
Nozaki, K.; Beh, C.H.; Mizuno, M.; Isobe, T.; Shiroishi, M.; Kanda, T.; Amano, Y. (2008), Screening and investigation of dye decolorization activities of Basidiomycetes. J Biosci Bioeng, 105, 69-72.

OECD Guidelines for the Testing of Chemicals. Guideline 202: Daphnia sp. Acute Immobilisation Test (2004), Organization For Economic CoOeperation And Development, Paris.

Pajot, H.F.; de Figueroa, L.I.C.; Farina, J.I. (2007) Dyedecolorizing activity in isolated yeasts from the ecoregion of Las Yungas (Tucumán, Argentina). Enzyme Microb Tech, 40, 1503-1511.

Pearce, C.I.; Loyd, J.R.; Guthrie, J.T. (2003) The removal of colour from textile wastewater using whole bacterial cells: a review. Dyes Pigments, 58, 179-196.

Pessis, A.M. (1998) Parque Nacional Serra da Capivara. Perfil Sócio-econômico. Área de Preservação permanente. Municípios de Coronel José Dias e São Raimundo Nonato. FUMDHAM/SUDENE, Recife.

Shiny, K.J.; Remani, K.N.; Nirmala, E.; Jalaja, T.K.; Sasidharan, V.K. (2005) Biotreatment of wastewater using aquatic invertebrates, Daphnia magna and Paramecium caudatum. Bioresource Technol, 96, n.1, 55-58.

Stemberger, R.S. (1981) A general approach to the culture of planktonic rotifers. Can J Fish Aquat Sci, 38, 721-724.

Vanhulle, S.; Trovaslet, M.; Enaud, E.; Lucas, M.; Sonveaux, M.; Decock, C.; Onderwater, R.; Schneider, Y.-J.; Corbisier, A.-M. (2008) Cytotoxicity and genotoxicity evolution during decolorization of dyes by White Rot Fungi. World $J$ Microb Biot, 24, 337-344.

Yang, O.; Li, C.; Li, H.; Li, Y.; Yu, N. (2009) Degradation of synthetic reactive azo dyes and treatment of textile wastewater by a fungi consortium reactor. Biochem Eng J, 43, 225-230.

Yang, Q.; Yediler, A.; Yang, M.; Kettrup, A. (2005) Decolorization of an azo dye, Reactive Black 5 and $\mathrm{MnP}$ production by yeast isolate: Debaryomyces polymorphus. Biochem Eng J, 24, 249-253.

Zheng, Z.; Levin, R.E.; Pinkham, J.L.; Shetty, K. (1999) Decolorization of polymeric dyes by a novel Penicillium isolate. Process Biochem, 34, 31-37.

Received: July 23, 2009; Revised: July 02, 2010; Accepted: February 28, 2011 